\title{
EFFECTIVE COMMUNICATION WITH CULTURAL HERITAGE USING VIRTUAL TECHNOLOGIES
}

\author{
R. M. Reffat ${ }^{\text {a, }}$, E. M. Nofal ${ }^{\text {b }}$ \\ Architectural Engineering Department, Faculty of Engineering, Assiut University, Egypt \\ a rabee@aun.edu.eg; ${ }^{b}$ esnofal@yahoo.com
}

KEY WORDS: Virtual heritage, Effective communication, Cultural heritage

\begin{abstract}
:
Cultural heritage is neither static nor stable. There is a need to explore ways for effectively communicating with cultural heritage to tourists and society at large, in an age of immediacy, a time of multiple realities and to multi-cultural tourists. It is vital to consider cultural heritage as a creative and relational process where places and communities are constantly remade through creative performance. The paper introduces virtual technologies as an approach to attain effective communication with cultural heritage. This approach emphasizes the importance of "user, content and context" in guiding the production of virtual heritage, as opposed to technology being the sole motivator. It addresses how these three issues in virtual heritage need to be transformed from merely representing quantitative data towards cultural information using the proposed effective communication triangle through representing meaningful relationships between cultural heritage elements, users and context. The paper offers a focused articulation of a proposed computational platform of "interactive, personalized and contextual-based navigation" with Egyptian heritage monuments as a one step forward towards achieving effective communication with Egyptian cultural heritage.
\end{abstract}

\section{ADVANTAGES OF VIRTUAL TECHNOLOGIES IN CULTURAL HERITAGE}

The term "heritage" broadly refers to the study of human activity not only through the recovery of remains, as is the case with archaeology, but also through tradition, art and cultural evidences, and narratives. However, "virtual heritage" $(\mathrm{VH})$ is a term used to describe works that deals with virtual-reality (VR) and cultural-heritage (Roussou, 2002). In general, virtual heritage and cultural heritage have independent meanings: cultural heritage refers to "properties and sites with archaeological, aesthetic and historical value" and "virtual heritage" refers to the instances of these properties and sites within a technological domain (Rahaman et al, 2010). The virtualization of heritage means to actualize the heritage contents digitally and to simulate it using computer graphics technology. The features of "virtual heritage" include facilitating synthesis, conservation, reproduction, representation, digital reprocessing, and displaying cultural heritage using the advancements of VR technologies (Roussou, 2002). Mixing VR technologies with the real-world is referred to as "Mixed Reality" (MR). Milgram et al (1994) presented the reality-virtuality continuum. One end of the continuum contains the real environment (reality), while the other end features the virtual environment (virtuality). Everything in between is a mixed reality. A Mixed Reality system merges the real world and virtual worlds to produce a new environment wherein physical and digital objects co-exist and interact. Reality here means the physical environment, in this context often the visible environment, as seen directly or through a video display (Siltanen, 2012).

With the advancement of technology, digital heritage projects have enhanced their capability from linear limited interactivity to non-linear immersive environment. Due to advanced computer hardware and high-end graphics cards, present trends in virtual reality applications are motivated towards the use of immersive technology for real-time interaction with high detail. Rahaman et al (2010) investigated the levels of interaction and associated platforms and interfaces using different technologies in digital heritage. In order to expect others to get excited about ancient cultures or expect them to grasp the implications of the evidence, it is important to introduce an interactive approach in 3D platforms, as noted by Sanders (2008) "the past did not happen in $2 D$ and that it cannot be effectively studied or taught as a series of disconnected static images".

Some of the advantages that Virtual Reality contributes to Architectural Heritage include (El-Razaz, 2007):

- Documenting, recording and conserving international heritage all over the world.

- Virtual Recovery of the Lost Heritage.

- Helping in the education process for students, especially architecture students and virtually transfer them to another world and make them feel as if they were walking at the site with its details in the past.

- Developing a rich library for architects to help them in restoring historical sites.

- Spreading native culture, heritage and tradition which contribute to attracting tourists to the country.

Furthermore, Reffat (2010) outlined some of the opportunities that the virtual heritage approach offers in enhancing both quality of cultural heritage and tourism in its diversified forms including:

- Recreating culture and reviving the past: "bridge between the modern user and the ancient culture"; using 3D virtual environments can enhance the virtual heritage.

- Heritage preservation: 3D virtual models contain accurate data and help for restoration

\footnotetext{
${ }^{1}$ Corresponding author
} 
- Presenting the past and present at the heritage site: visitors can imagine being a part of a story that happened a long time ago using augmented reality.

- Edutainment (education and entertainment) of cultural heritage: visitors get more involved with activities and increase social interaction to develop collaborative learning experiences.

\section{EXAMPLES OF VR APPLICATIONS IN CULTURAL HERITAGE}

The actual records of culture are constituted from performances to artefacts that have been created in a persistent manner but inevitable decay. This is depicted in the notion of cultural heritage where it consists of what is called "Tangible Heritage" such as buildings, artefacts and media as well as the "Intangible Heritage" containing art expressions (music, dancing, literature etc.) (Foni et al, 2003). Some of the examples of utilizing VR in cultural heritage are presented in this section.

\subsection{Tangible cultural heritage}

Augmented Reality In Cultural Heritage (ARICH) project is used to visualize archaeological artefacts (Mourkoussis et al, 2002). The input to this system is $2 \mathrm{D}$ architectural plans provided by the archaeologists. Then, using $3 \mathrm{ds} \max$ from Discreet, semi-automated modelling takes place based on scripts, which are algorithms written in MaxScript (the 3ds scripting language), developed as part of this project. Manual modelling (such as reconstruction of missing parts) are used to refine the model, or photogrammetry techniques are used to digitize 3D models. The output of the system is a 3D model (geometry, material colour, texture, lighting, information) for interactive rendering or visualization. A general overview of the system is illustrated in Figure 1.

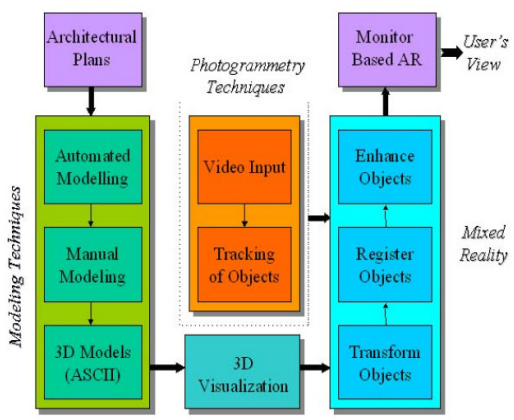

Figure 1. A general view of ARICH system (Mourkoussis et al, 2002).

Another project called Augmented Representation of Cultural Objects (ARCO) that has been developed to be used in museums in order to offer an augmented virtual representation for the cultural objects in a fast, simple and flexible method of capturing, refining, storing and presenting archives, while allowing for advanced searching, retrieval and browsing of archives -both locally and via the web- subject to security that protects museum Intellectual Prosperity Rights (IPR). Figure 2 depicts the overall architecture of ARCO (Mourkoussis et al, 2002).

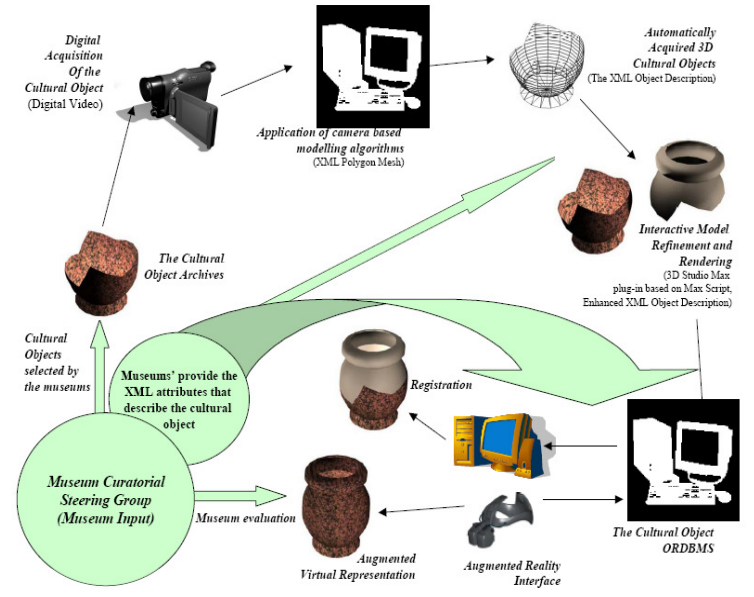

Figure 2. The overall architecture of ARCO (Mourkoussis et al, 2002).

Furthermore the Augmented Reality system can be used for physical restoration by equipping the restorations workers with an AR display; the information about the physical repair can be added on the real view of the worker, and he can use the repair equipment, without referring to a separate paper or electronic manual. An example of such implementations was conducted by Peral et al (2005) and illustrated in Figure 3.

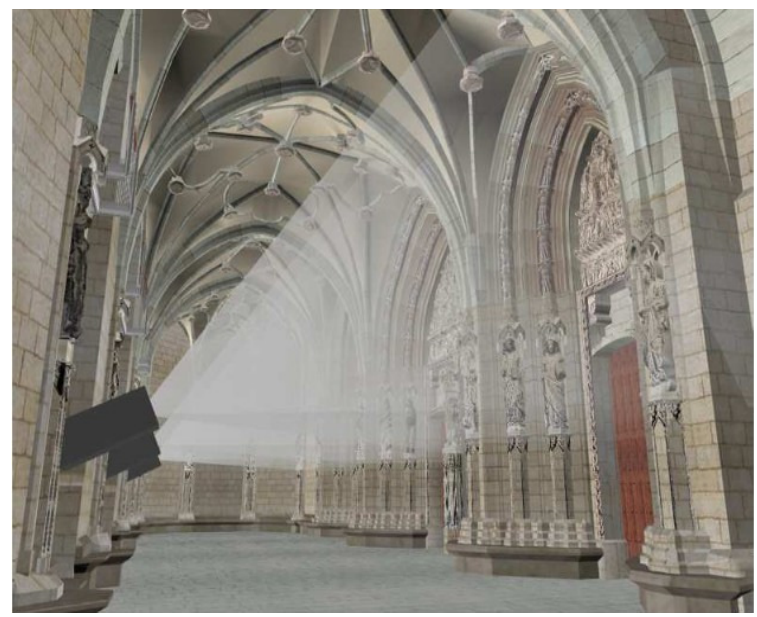

Figure 3. Interactive 3D application AR using viewing the heritage 3D model of the portico on the real one using three parallel projectors and their light beams (Peral et al, 2005).

\subsection{Intangible dimensions of sites and artefacts}

An Augmented Reality (AR) paradigm has been introduced to cultural heritage by Aguiló et al (2001), who proposed a system that establishes a dialog between users and archaeological objects right in place. The system is based on an interactive device in an augmented reality system, which allows visitors to see real objects and reconstructions of the past, at the same time, as shown in Figure 4. This system is based on user cantered design models like storyboards, scenarios and video prototypes. This prototype foresees the user possible acts and simulates the future system, which has been evaluated by the visitors and two focus groups during the visit to the archaeological site of Arbeca in Spain. 


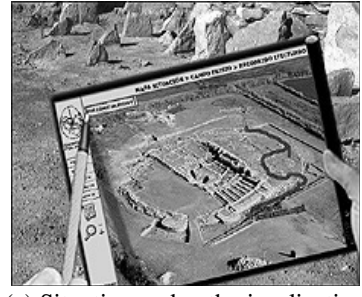

(a) Situation and path visualization

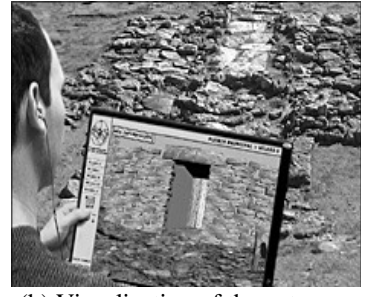

(b) Visualization of the entrance reconstruction
Figure 4. Visit to the fortress of Arbeca in augmented reality (Aguiló et al, 2001).

Another approach has been presented by Foni et al (2003), to establish a complete real-time interactive digital narrative visualisation of the Namaz Pray of a simulated Ottoman Imam in the 16th century virtually restored mosque of Küçük Aya Sofya (previous St. Sergius and Bacchus church) as well as in the Hagia Sophia mosque (previous cathedral of Hagia Sophia), in Istanbul, Turkey. Figure 5 illustrates the results of the adoption of the VHD++ framework for the rapid creation of the immersive VR application prototype. Such virtual heritage simulations are a fundamental aspect for the full understanding of the historical and social development of vast communities and form a 'virtual material witness' of the process of civilization.
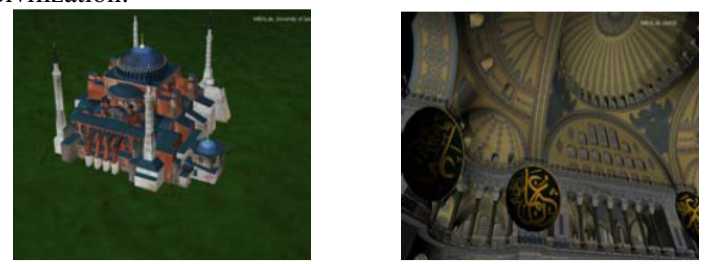

(a) Hagia Sophia Ottoman Mosque
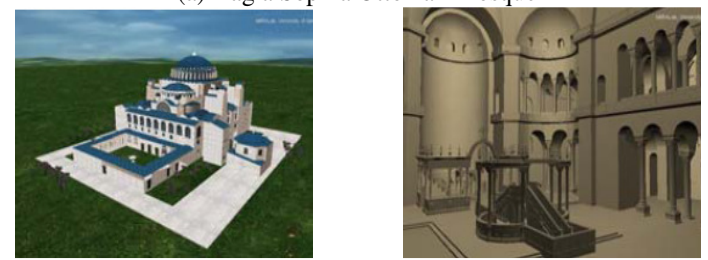

(b) Hagia Sophia Byzantine Church
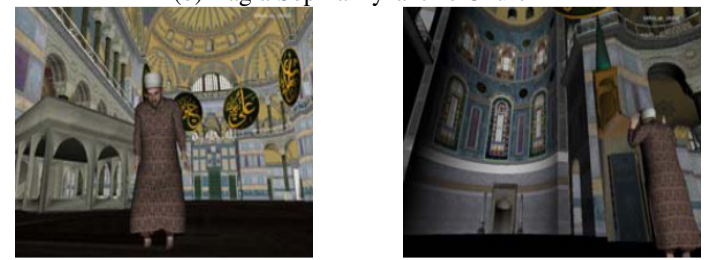

(c) Hagia Sophia Mosque with real-time virtual
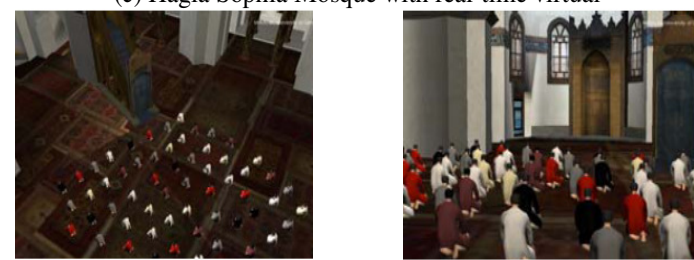

(d) S. Sergius \& Bacchus Mosque with virtual characters

Figure 5. VHD++ real-time framework (Hagia Sophia) (Foni et

$$
\text { al, 2003). }
$$

As a part of the project "PRISMA- Augmented vision for Cultural Tourism Applications"; a group of researchers have developed an interactive visualization system based on Augmented Reality Technologies and the integration into a cultural tourism application (Fritz et al, 2005). This prototype has been validated and evaluated in a real Cultural Tourism destination, by selecting an object of interest for example a cultural building in the area; a virtual walkthrough could be started. That would port the user from the real position into the building letting him move around there and contemplate the virtual interior of the building. Figure 6 shows the building of the augmented view. Furthermore, Fritz et al thought about the possibility of choosing special marked positions in the area to virtually zoom there and offer a panoramic view from that position, in which the user can navigate using the binoculars.

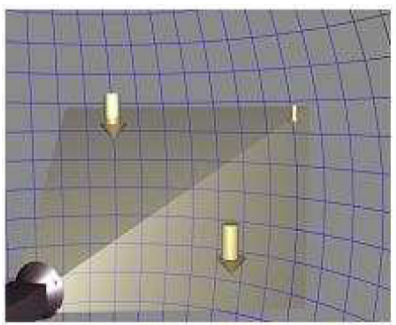

(a) The virtual world

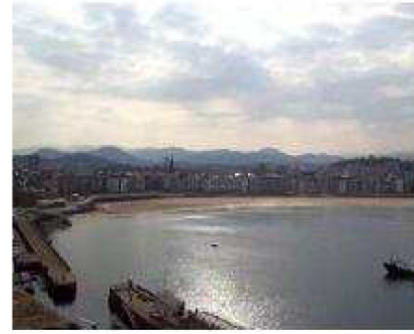

(b) The real world

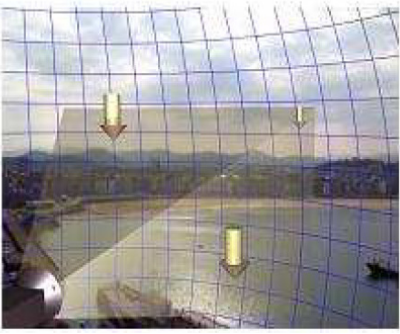

(b) The augmented view

Figure 6. Building the Augmented view (Fritz et al, 2005).

The system "ARCHEOGUIDE" was developed to transform the method of viewing and learning about a cultural heritage site for the visitors. In this beginning of system, the visitors are providing with user profile representing their interest and background. Then, the system provides a set of predefined tour that the visitor must choose. From that, the system will guide the visitor through the site, acting as a special instrument. To display AR reconstruction of the temples and other monuments of the site, the system will depend on the position-orientation tracking component. Figure 7 illustrates the natural view from the visitor's viewpoint and followed by the same view augmented with the 3D model. The site visitors are wearing AR glasses to see the 3D image display. This system is handy unit carried by visitor during their site tours and communication networks (Noh et al, 2009).

In the project of "Ancient Pompeii", video-see-through HMD is used to capture real scene. After that, this scene was blended by precise real-time registration and $3 \mathrm{D}$ modelling of realistic complete simulation of virtual humans and plants in a real-time storytelling scenario based on the environment, as illustrated in Figure 8 . These virtual humans are completely with real-time body, speech, face expression and cloth simulation. The project was performed in a mobile and wearable setup with markerless 
tracked camera and was implemented in real-time (Noh et al, 2009).

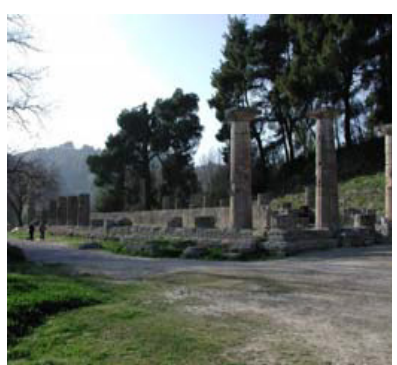

(a) Original image

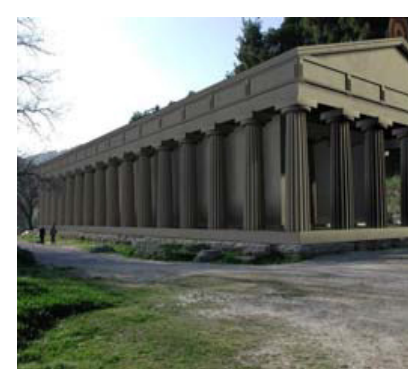

(b) Augmented scene
Figure 7. Ancient Olympic Games (Vlahakis et al, 2001 in Noh et al, 2009).

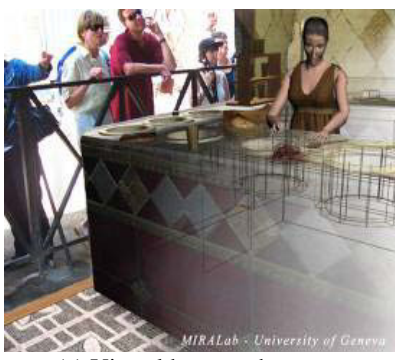

(a) Virtual human character

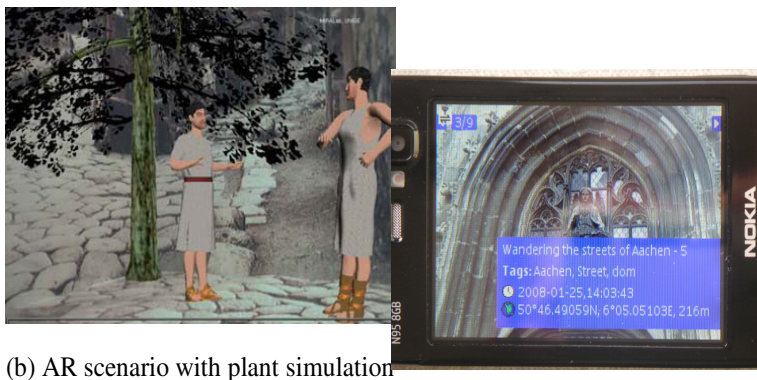

(b) AR scenario with plant simulation
Information and Communication) to demonstrate future mobile social software applications with real-time multimedia processing and semantic enrichment of multimedia materials by complex collaboration of user communities. This scenario also works with mobile technologies (Figure 10) for an on-going semantic enrichment of multimedia materials in professional discourses by: a) multimedia annotation and sharing; b) semantically enriched search and retrieval; and c) recontextualization of multimedia artefacts in knowledge intensive collaboration processes like storytelling. They demonstrated how to integrate such a scenario in a concrete community taking a case study; the Bamiyan Valley Development community.
Figure 8. Ancient Pompeii (Magnenat-Thalmann et al, 2006).

Another approach was to achieve performing informative based 3D reconstructions of architectural heritage sites in Mecca as a guidance engine for Mecca visitors which will have great impacts on facilitating visitors' experiences and improving the efficiency of crowd management in Mecca during Hajj and Umrah. A potential example for utilizing handheld informativebased 3D that manifests physical world meeting the virtual world in the holy city of Mecca is proposed by Reffat (2011), it is shown in Figure 9. Augmented Reality superimposing information onto the live image captured by a cell phone's camera. The Mecca visitors may point their cell phone at a place, for instance the Holy Kaaba, and information about that specific place appears on the screen.

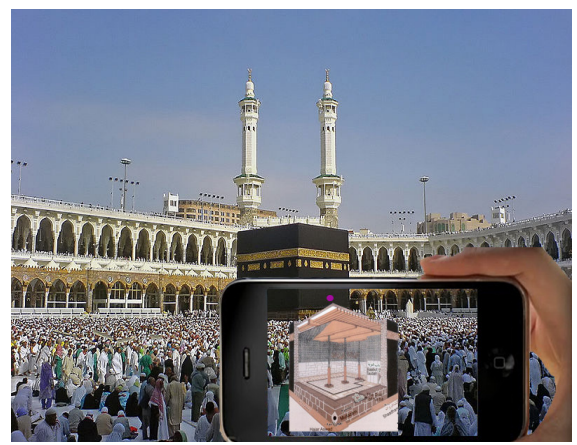

Figure 9. Utilizing handheld informative-based 3D that manifest physical world meeting the virtual world in the holy city of Mecca (Reffat, 2011).

2.3 Contextualization of virtual heritage within social, economic and political structure

In order to incorporate mobile technologies in cultural heritage management activities, Klamma et al (2009) presented the Virtual Campfire scenario. This scenario has been established in the German excellence cluster UMIC (Ultra High Speed Mobile

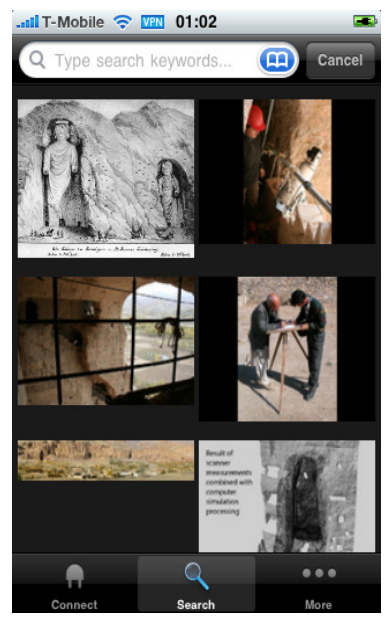

(a) Nokia N95 version

(b) iPhone version

Figure 10. The mobile media viewer (Klamma et al, 2009).

\section{VIRTUAL TECHNOLOGIES FOR EFFECTIVE COMMUNICATION WITH CULTURAL HERITAGE}

Considering Virtual Reality as a communication process, there are three levels of abstraction that have to be considered: the syntactic level, the semantic level and the pragmatic level. The technical choices descend by the definition of these points. The syntactic level of a communication concerns functions and model implemented, including signs and symbols whose meanings and semantics have to be defined in the second step of design to be interpreted and recognized by users. The pragmatic aspect is realized when the representation is finalized to the end users' needs, considering the emotional state induced by Virtual Reality and how users' emotional state and perception are influenced by Virtual Reality (Folgieri, 2011).

There is a need to explore ways for effectively communicating with cultural heritage to tourists and society at large, in an age of immediacy, a time of multiple realities and to multi-cultural tourists. It is vital to consider cultural heritage as a creative and relational process where places and communities are constantly remade through creative performance. The paper introduces virtual technologies as an approach to attain effective communication with cultural heritage. This approach emphasizes the importance of "user, content and context" in guiding the production of virtual heritage, as opposed to technology being the sole motivator. It addresses how these three issues in virtual heritage need to be transformed from merely representing quantitative data towards cultural information. This is proposed through representing meaningful relationships between cultural heritage elements, users and 
context. This is manifested by the proposed effective communication triangle approach illustrated in Figure 11. Through the relationship between the interests of users (users), according to their features (content), and location (context) the computational system shall possess some kinds of intelligence in order to fulfil its goal while utilizing the augmented reality approach to visualize, enhance, interact, and manipulate varieties of Egyptian architectural heritage.

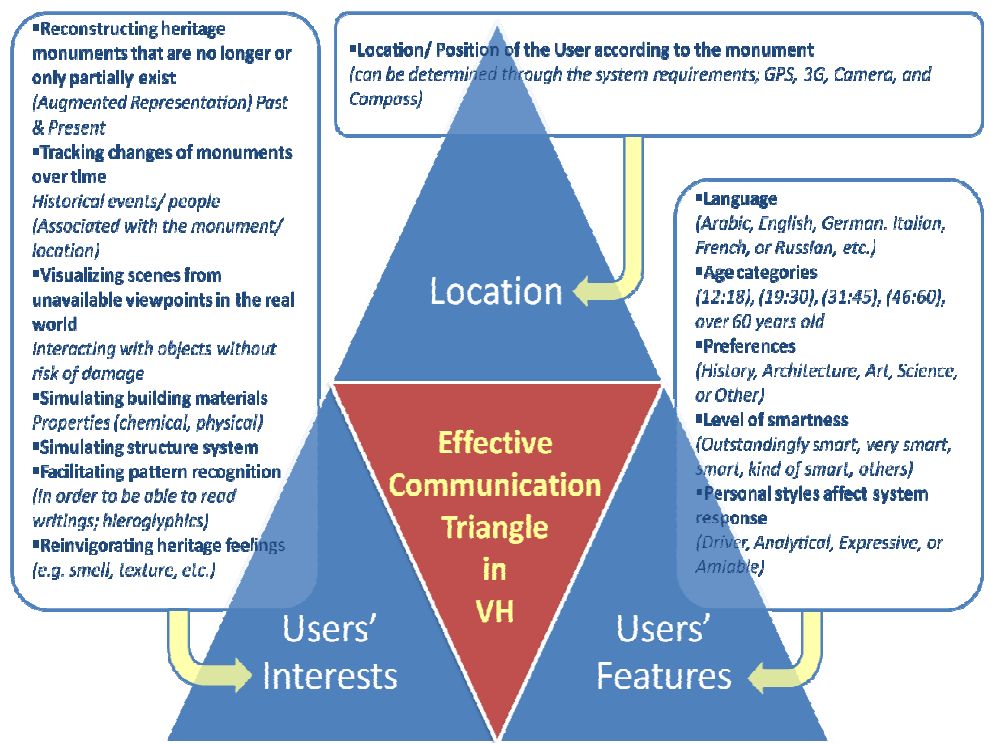

Figure 11. The proposed effective communication triangle approach for virtual heritage.

A focused articulation of a proposed computational platform of "interactive, personalized and contextual-based navigation" with Egyptian heritage monuments as a one step forward towards achieving effective communication with Egyptian cultural heritage is presented below using the HIPO framework (Hierarchy, Input, Process, Output) and system flow chart.

The Hierarchy Input Process Output (HIPO) framework for the proposed computational system consists of two phases; each phase has two modules, as shown in Figure 12.

- First Phase: User features (user): Language, Age, Preference, Smartness degree, and Personal Style.

- Second Phase: The optimal responses (content) to users' actions in terms of: heritage reconstructing, events/ peoples, building materials, structural system, and pattern recognition. Depending on to user's location (context) the system responds to the visualizing scenes and the augmented representation.

-

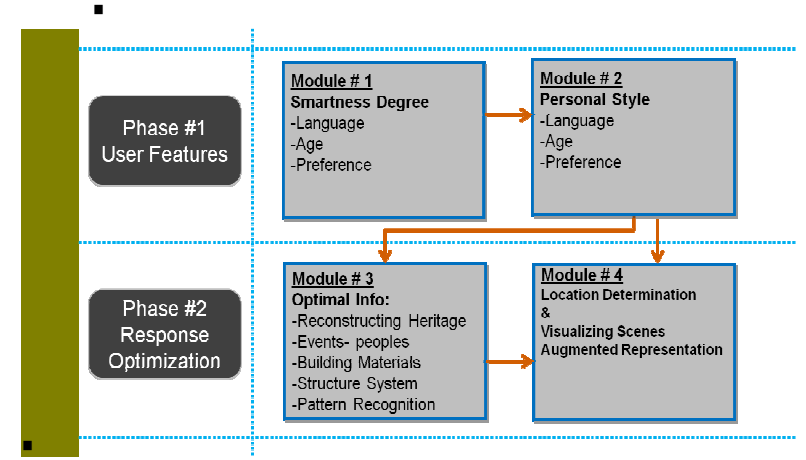

Figure 12. HIPO for the proposed computational system interactive, personalized and contextual-based navigation" with Egyptian heritage monuments.

Figure 13 shows the system's flowchart for obtaining the optimal information to users according to their interests and features.
A thorough analysis of the relationship between users' features and interests has been conducted. One of the features of users is the personal style, which has been classified into four categories: Driver, Analytical, Expressive, and Amiable, as illustrated in the right-side in the table. In order to achieve an effective communication with cultural heritage using virtual technologies, a matrix has been developed as illustrated in Table 1 to outline the types of information to be communicated to users and the recommended level of communication in relation to the users' features taking into account the acquired users' features and location. This informs and guides the process of achieving effective communication in virtual heritage as a roadmap.

\section{CONCLUSION}

This paper introduced virtual technologies as an approach to achieve effective communication with cultural heritage. The "user, content and context" has been given a paramount importance in guiding the production of virtual heritage, as opposed to technology being the sole motivator, wherein these three issues in virtual heritage are transformed from merely representing quantitative data towards cultural information using the proposed effective communication triangle through representing meaningful relationships between cultural heritage elements, users and context. The paper offered a focused articulation of a proposed computational platform of "interactive, personalized and contextual-based navigation" with Egyptian heritage monuments as a one step forward towards achieving effective communication with Egyptian cultural heritage. The future implementation and application of the proposed computational system will be tested by the users (tourists) at selected Egyptian heritage monuments. The findings, analysis and required refinements of this application will be reported accordingly. 
Table 1. A Matrix of thorough analysis of the relationship between users' features and interests in cultural heritage

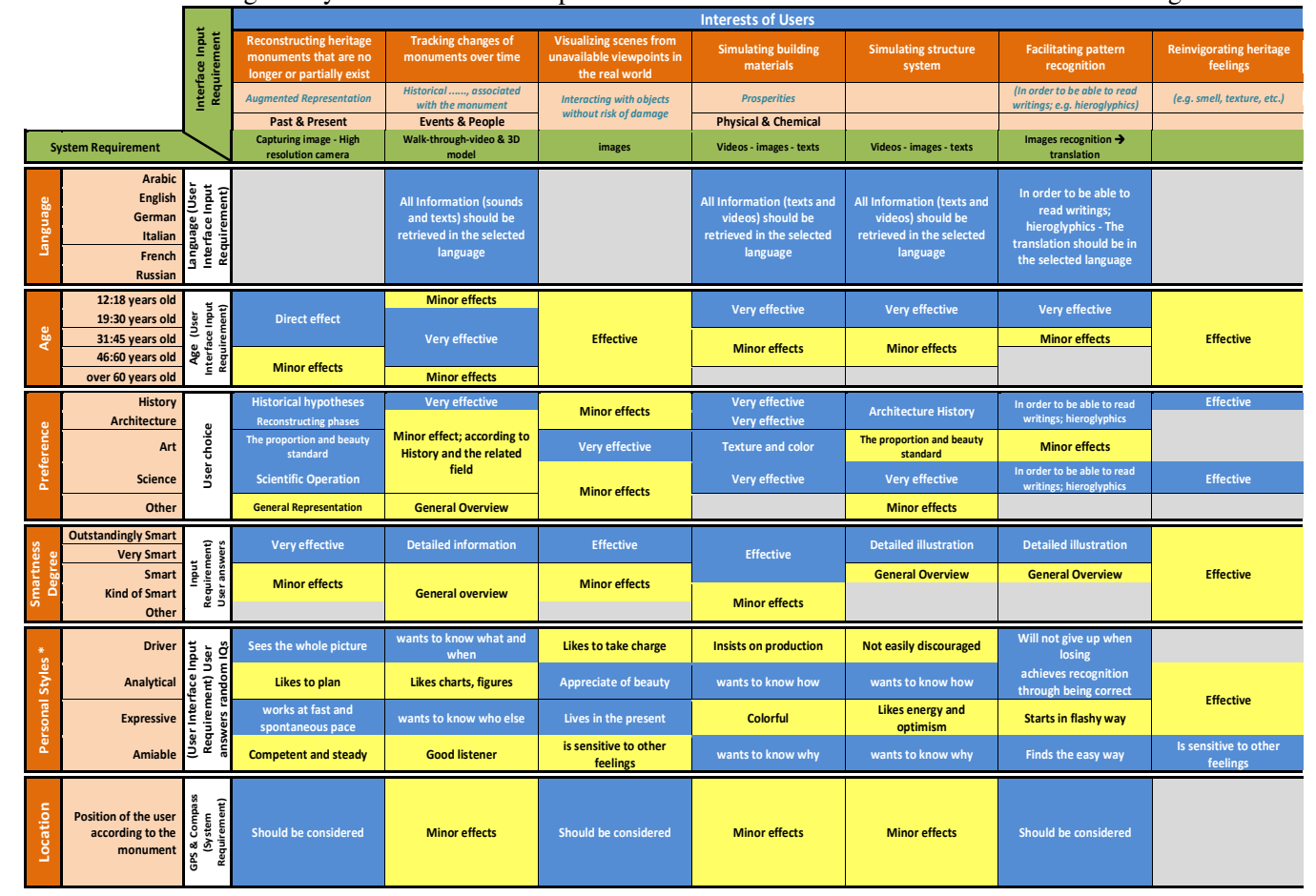

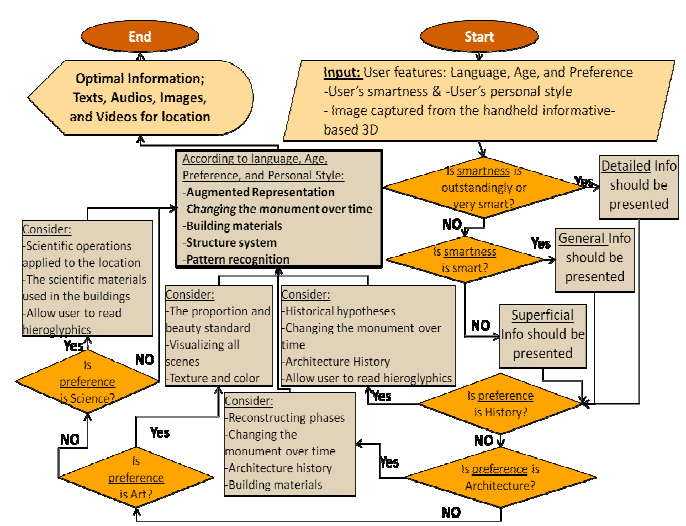

Figure 13. A flowchart of the computational system for obtaining the optimal information to users based on their interests and features.

\section{REFERENCES}

Aguiló, C., Lorés, J. and Junyent, E., 2001, Enhanced Cultural Heritage Environments by Augmented Reality Systems, VSMM'01, pp. 357-364

El-Razaz, Z., 2007. Virtual Heritage in the Digital Era, ASCAAD 2007, pp. $149-164$

Folgieri, R., 2011. VR for Cultural Heritage Valorization: A Communication Problem", Proceedings of Electronic Imaging \& The Visual Arts, pp. 146-151

Foni, A., Papagiannakis, G. and Magnenat-Thalmann, N, 2003. A Virtual Heritage Case Study: A Modern Approach to the Revival of Ancient Historical or Archaeological Sites Through Application of 3D Real-Time Computer Graphics, MIRALab, University of Geneva, Switzerland.

Fritz, F. M., Susperregui, A. and Linaza, M. T., 2005. Enhancing Cultural Tourism experiences with Augmented Reality Technologies", The $6^{\text {th }}$ International Symposium on Virtual Reality, Archaeology and Cultural Heritage VAST.

Klamma, R., Toubekis, G., Cao, Y., Renzel, D., Jarke, M. and Jansen, M., 2009, Virtual campfire - cultural heritage management and presentation on mobile devices based on interoperable cross platform MPEG-7 multimedia web services. Proceedings of 22nd CIPA
Symposium - Digital Documentation, Interpretation and Presentation of Cultural Heritage, Kyoto, Japan.

Magnenat-Thalmann, N. and Papagiannakis, G., 2006. Virtual Worlds and Augmented Reality in Cultural Heritage Applications. In Recording, Modelling and Visualization of Cultural Heritage Baltsavias et al. (eds), pp. 419-430, Taylor \& Francis Group.

Milgram, P., Takemura, H., Utsumi, A. and Kishino, F., 1994. Augmented Reality: A Class of Displays on the Reality-Virtuality Continuum", Proceedings of SPIE, Vol. 2351, Telemanipulator and Telepresence Technologies. pp. 282-292.

Mourkoussis, N., Liarokapis, F., Darcy, J., Pettersson, M., Petridis, P., Lister, P.F. and White, M., 2002. Virtual and Augmented Reality Applied to Educational and Cultural Heritage Domains. Proceedings of BIS 2002, Proznan, Poland.

Noh, Z., Sunar, M. S. \& Pan, Z., 2009. A Review on Augmented Reality for Virtual Heritage System. Edutainment '09 Proceedings of the 4th International Conference on E-Learning and Games: Learning by Playing. Game-based Education System Design and Development, pp. 50-61.

Peral, R., Sagasti, D. and Sillaurren, S., 2005. Virtual restoration of cultural heritage through real-time 3D models projection. Proceedings of the $6^{\text {th }}$ International Symposium on Virtual Reality, Archaeology and Cultural Heritage VAST, Pisa, Italy

Rahaman, H., Rashid, M. and Rahman M., 2010. Heritage Interpretation: Collective Reconstruction of Sompur Mahavihara, Bangladesh. $16^{\text {th }}$ International Conference on Virtual Systems and Multimedia (VSMM), pp. 163:170

Reffat, R. M., 2010.Utilization of Digital Technologies for Enriching Heritage Cities, The Holy City of Madinah as an Example. Proceedings of the first International Conference for Urban Heritage In the Islamic Countries (UHIC), Riadh, Saudi Arabia.

Reffat, R. M., 2011. Enriching the Restoration and Utilization of Architectural Heritage Sites: An Augmented Reality Approach (Makkah Al-Mukarramah as a case study)", Proceedings of the National Built Heritage Forum, Research \& heritage: Research Papers on Architectural Heritage, Saudi Commission for Tourism and Antiquities, Jeddah, Saudi Arabia, pp. 115-129.

Roussou, M., 2002. Virtual Heritage: From the Research Lab to the Broad Public. Virtual Archaeology, pp. 93-100

Sanders, D., 2008. Why do Virtual Heritage?. A publication of the Archaeological Institute of America.

Siltanen, S., 2012. Theory and applications of marker-based augmented reality. VTT Technical Research Centre of Finland. 